\title{
Directed Motivational Currents (DMCs) in Self-directed Language Learning: An Interpretative Phenomenological Analysis
}

\author{
Ismail Xodabande, Esmat Babaii \\ Kharazmi University \\ Correspondence concerning this article should be addressed to Ismail Xodabande, Department of Foreign \\ Languages, Kharazmi University, No. 43, Shahid Mofatteh Street, Tehran, Iran. \\ E-mail: ismail.kh.tefl@gmail.com

\begin{abstract}
Directed Motivational Currents (DMCs) postulated as a novel motivational construct in second language acquisition (SLA) research to explain periods of intense and enduring behavior in pursuit of a highly valued goal or vision. Nonetheless, much of the discussion related to this new motivational phenomenon has remained theoretical, and only a limited number of empirical studies have investigated its various dimensions in language learning. The current qualitative study employed interpretative phenomenological analysis (IPA) to explore a period of intense motivation experienced by an Iranian language learner in self-directed and mobile assisted language learning. The findings provided further empirical evidence for the triggering stimulus and the core characteristics of DMCs in terms of goal/vision orientedness, a salient facilitative structure, and positive emotionality in explaining the essence and the universal meaning of the phenomenon experienced by the participant of the current study.
\end{abstract}

Keywords: directed motivational currents (DMCs), mobile-assisted language learning (MALL), motivation, self-directed language learning, positive emotions

\section{Introduction}

Research on second language (L2) learning motivation as an important cause of variability in language learning success, has been a major topic within second language acquisition (SLA) research for over five decades (Ushioda \& Dörnyei, 2012), and has seen an "unprecedented boom" during the past ten years (Boo et al., 2015). Recently, in line with the current emphasis on the complexity and situated nature of L2 learning motivation, Dörnyei and his colleagues introduced a new motivational construct called Directed Motivational Currents (DMCs), to explain periods of intense and enduring motivational drive in pursuit of a highly valued goal or vision (Dörnyei et al., 2015; Dörnyei, Ibrahim, et al., 2014; Dörnyei, Muir, et al., 2014; Muir \& Dörnyei, 2013). The experience of DMCs is a vision-led, self-regulation effort that is associated with "the excitement of journeying down a 'motivational highway' towards new pastures" (Dörnyei, Ibrahim, et al., 2014, p. 103), and "emerges within the framework of a salient structure of behavioural acts - many of them being routines performed on 'motivational autopilot' - which are permeated by the sense of elevated emotionality associated with approaching a coveted prize” (Dörnyei, Muir, et al., 2014, p. 27).

It has been argued that DMCs can align a diverse set of motivational factors working simultaneously in a complex system (Dörnyei, Ibrahim, et al., 2014; Muir \& Gümüş, 2020), and they rise "when a specific set of initial conditions fall into place to allow for directed motivational energy to be charged into a behavioural sequence that is aimed towards a predefined explicit goal” (Muir \& Dörnyei, 2013, p. 359). Despite being a novel conceptualization of language learning motivation, different aspects of DMCs are well-established in mainstream theories of motivation in psychology (Dörnyei et al., 2015), and this new construct has great potential to act as a fundamental organizer of motivational impetus in both individual- and group-level language learning (Dörnyei, Muir, et al., 2014; García-Pinar, 2020; Ibrahim \& Al-Hoorie, 2019; Zarrinabadi et al., 2019). Nevertheless, although the experiences of DMCs are shared by many individuals in their lives, as well as language learning endeavors (Dörnyei et al., 2015), much of the discussion related to this new motivational construct has remained theoretical in nature, and only a limited number of empirical studies have been 
conducted to investigate it in language learning (García-Pinar, 2020; Henry et al., 2015; Pietluch, 2018; Safdari \& Maftoon, 2017; Zarrinabadi \& Khodarahmi, 2021; Zarrinabadi \& Tavakoli, 2017). In order to fill part of this gap, the current study aimed to investigate this phenomenon as experienced by an Iranian language learner, in the self-directed and mobile-assisted learning of German as a foreign language. The next section provides theoretical and empirical backgrounds for the DMCs, and locates the current study within the growing body of knowledge with respect to understanding this motivational phenomenon.

\section{Literature Review}

As a unique and highly distinctive motivational state, DMCs arise when a personal goal of great importance aligns with a structured pathway of action, which becomes automatized and amplified by the energy generated in the pursuit of the goal (Henry, 2019). In this regard, DMCs are different from ordinary motivated behavior, contain a greater sense of urgency, and alter established patterns of daily life (Henry et al., 2015). Despite the fact that different people experience such motivational states differently, it has been argued that DMCs have three core characteristics of being goal/vision-oriented, having a salient facilitative structure, and having positive emotionality (Dörnyei et al., 2015; Dörnyei, Ibrahim, et al., 2014; Dörnyei, Muir, et al., 2014; Henry, 2019).

Being goal/vision-oriented, a DMC is always directional, which means that it leads the individual towards a clearly defined and highly valued goal or end state (Dörnyei, Muir, et al., 2014). This provides a "gravitational effect on motivational energy, systematically channeling behavior toward activities perceived as enhancing the likelihood of goal attainment and away from other, unrelated activities that compete for the learner's time" (Henry et al., 2015, p. 331). Nonetheless, despite the unifying power of a clearly set goal, a DMC cannot sustain its strength without having a sensory component, which is vision. As a key factor of DMCs, vision is a goal that is enriched by the reality of the actual experience of the achievements (like seeing oneself in the desired state) (Dörnyei \& Kubanyiova, 2013). In this regard, the power and the intensity of a DMC is highly dependent on the quality of the visionary dimension that is superimposed onto the guiding goal (Dörnyei et al., 2015; Henry et al., 2015).

The second major characteristic of a DMC relates to its salient facilitative structure, which means that this phenomenon has a clear pathway from its rise to the end point. According to Henry et al. (2015), the structure of a DMC has three main components: (1) a set of recurring behavioral routines aligned with the goal achievement, (2) a process of regular checks for the sub-goals and positive feedback for progress, and (3) clear and identifiable starting and ending points. In this regard, Dörnyei et al. (2015) believe that "a DMCs does not simply 'drift' into being, but rather is triggered by a specific event, or by a group of individual factors acting in concert” (p. 58). In fact, a clear starting point (Muir \& Dörnyei, 2013), as well as a combination of contextual, personal, and time factors (Dörnyei, Ibrahim, et al., 2014), are required for the successful launch of a DMC. Moreover, an effective launch needs to be followed by the establishment of a set of behavioral routines, which like domino pieces "will all fall one after another from a single push because they are all part of the same chain" (Dörnyei, Muir, et al., 2014, p. 14). Closely related to this aspect is the role of progress checks and affirmative feedback, as the individual being caught up in a DMC makes use of proximal sub-goals to break the pathway into smaller steps (Dörnyei et al., 2015), and in the process needs to receive positive feedback to have a clear and ongoing perception of where she/he is on the way towards achieving the goal (Dörnyei, Ibrahim, et al., 2014).

Finally, since pursuing highly valued goals is related to individuals' identities and contributes to actualizing their potentials, the process of learning will be accompanied by intense pleasure, satisfaction, and fulfilment (Henry et al., 2015). The positive emotionality in a DMC arises from the realization that an individual is approaching the highly valued goal by completing a set of sub-goals, which create more enjoyment and emotional loading. In this regard, the experience of an elevated emotional state helps to sustain the overall motivation and long-term engagement (Dörnyei et al., 2015). It is important to note that this elevated emotional state and enjoyment is not due to the intrinsic value of the activity, but results from making meaningful progress toward the vision that the individual created for the future (Dörnyei, Ibrahim, et al., 2014). 
Despite being a novel idea for capturing highly intensive motivational states, the theorizing of DMCs has strong links with well-known motivation theories in psychology (Dörnyei et al., 2015; Dörnyei, Ibrahim, et al., 2014; Dörnyei, Muir, et al., 2014). For example, DMCs share some features with flow theory (Csikszentmihalyi, $2014 \mathrm{~b}, 2014 \mathrm{a}$ ), such as being fully engaged in a goal-directed and highly interesting activity. A key distinction between the experience of flow and other entertaining activities is that in the former, the enjoyment originates from the task itself rather than any external material gains. In this regard, when experiencing flow, one loses a temporal connection to the past or future (losing track of time) and becomes fully engaged in the activity for the sake of the task itself. From this perspective, flow and DMCs share a number of defining features. More specifically, being completely engrossed in some highly motivating activity for a period of time that directs all attentional resources towards achieving a well-defined goal is the defining core of both constructs. Moreover, positive emotionality is a crucial element that generates enjoyment in flow and DMCs. Nevertheless, it has been also argued that flow and DMCs are different with respect to their scope (individual vs. group-based activities), the duration of tasks, the importance of goals within the two types of experiences, and factors related to individual differences (Ibrahim, 2016b). Additionally, DMCs share some aspects with goal setting theory, which aims to explain performance in relation to various goal attributes (Locke \& Latham, 2013). Building on mainstream motivation theories in psychology, the theory of DMCs aims to take into account both the role of motivational dispositions, and temporal factors over time (Dörnyei et al., 2015). In this regard, the DMC construct has significant theoretical and practical potential that needs further research and investigation (Dörnyei, Muir, et al., 2014).

Although the empirical research on DMCs is still in its infancy (Muir \& Gümüş, 2020), we have recently witnessed growing interest among second language learning motivation researchers to investigate various aspects of this motivational state at individual and group levels for language learning (García-Pinar, 2020; Ghanizadeh \& Jahedizadeh, 2017; Henry et al., 2015; Ibrahim, 2016b; Safdari \& Maftoon, 2017; Zarrinabadi et al., 2019; Zarrinabadi \& Khajeh, 2021; Zarrinabadi \& Khodarahmi, 2021; Zarrinabadi \& Tavakoli, 2017). The main focus of this growing body of knowledge has been testing the validity of the proposed framework for DMCs. In this regard, the majority of the studies conducted thus far have been confirmatory investigations that aimed to document and account for the participants' experiences in terms of the three components of the DMC framework. For example, in one of the early studies, Henry et al. (2015) investigated this phenomenon as experienced by three learners of Swedish as a second language, and their findings pointed to the validity of the proposed frameworks in terms of being goal/vision-oriented, a salient facilitative structure, and positive emotional loading. In another study, Safdari and Maftoon (2017) conducted a case study with a focus on the language learning experience of a 33-year-old Iranian woman. The findings from this study also provided empirical evidence for the three components of DMCs. Moreover, previous studies also indicated that the experience of DMCs are not unique to language learners, but such a phenomenon has been documented among language teachers (Zarrinabadi et al., 2019; Zarrinabadi \& Tavakoli, 2017). Additionally, research has indicated that the core components of DMCs are manifested in the shared experiences of groups of students as well (García-Pinar, 2020; Zarrinabadi \& Khajeh, 2021). Collectively, these studies have provided sound empirical evidence for the explanatory power of the original three-part framework proposed for DMCs.

In addition to the abovementioned validity studies, researchers have also focused on examining specific aspects of DMCs. For example, the triggering event of DMCs have been investigated and the findings revealed a number of factors such as "emergent opportunities, negative emotion, moments of realization/awakening, new information, and meeting others who shared the goal" (Ibrahim, 2017, p. 24) that have the potential to initiate intense motivational states among language learners. Zarrinabadi et al. (2019) also reported that teachers' comments, encouragement by close relatives, interacting with tourists, and failure to understand the target language use can give rise to DMCs. In a more recent study, Zarrinabadi and Khodarahmi (2021) explored the antecedents of DMCs among a group of language learners in Iran, and their findings indicated that "othersrelated factors (e.g. goal contagion and salient others) and social-situational factors (e.g. critical life incidents, ego threat, responsibility) triggered DMCs" (p.12). Moreover, Ibrahim (2016a) investigated the affective aspects of experiencing DMCs. The participants of the study were seven adult language learners and the finding revealed that all the participants felt strong positive emotions and regarded the DMCs as an enjoyable and happy experience. The study also indicated that the positive emotionality in the DMCs stemmed not only from the participants' language learning experiences, but also from the "judgements mainly through a constant feeling of acquiring new personal value and meaning in relation to discovering one's potential, developing important life skills, and becoming a different, unique and better person" (p. 278). 
Moving along these lines, the current study aimed to shed more light on DMCs in terms of self-directed language learning experience. This study is significant as for a large number of language learners, self-directed learning through mobile applications and websites is the primary source of language development (RosellAguilar, 2018). Nevertheless, these informal language learning environments have been less represented in existing research on second language acquisition in general (Arvanitis, 2019; Cole \& Vanderplank, 2016; Godwin-Jones, 2011; Loewen et al., 2020; Richards, 2015; Xodabande, 2018; Xodabande \& Atai, 2020), and the study of the motivational dimension in self-directed and technology-based language learning has remained largely limited (Chik, 2019; Gardner \& Yung, 2017). In order to fill part of this gap, the current study set out to investigate the launch of DMCs and the extent to which the core characteristics, as outlined above in general and positive emotional loading in particular, can account for our understanding of intense motivational states in self-directed language learning. In doing so, the following research question was addressed:

To what extent do the key components of the DMCs account for the experience of intense motivational states in self-directed language learning?

\section{Methodology}

\section{Study Design}

The current study used interpretative phenomenological analysis (IPA) (Aagaard, 2017; Eatough \& Smith, 2008, 2017; Smith et al., 2009), which is a qualitative research method concerned with the understanding of how individuals make sense of their major life experiences. The concept of 'experience' is of prime importance within the IPA method, as IPA is interested in what happens when the usual flow of daily experiences takes on a significance for individuals when something important happens to them (Eatough \& Smith, 2017). IPA aims to engage with these significant experiences through the reflections individuals make about the experience. To this end, IPA research is informed by double hermeneutics in which the researcher is trying to make sense of the participants trying to make sense of their major life experiences (Smith et al., 2009). In this regard, the researcher uses the same mental capacities as the participants, and tries to make sense of what is happening to them using their own accounts. Nevertheless, she/he is more systematic and self-conscious in making sense of the events.

The choice of a phenomenological method for the current study was motivated by several considerations. First, unlike other research methodologies that aim to identify similarities and differences among the participants, IPA aims to study the phenomenon under investigation as experienced and lived by only small number of individuals (Eatough \& Smith, 2008). In this regard, given that experiences with DMCs differ from one individual to the next (as they impact self-image, emotions, and identity, among others), IPA is best suited for investigating this intense motivational surge. Moreover, IPA allows the collection of rich data by giving the subject an opportunity to describe their lived experiences, subjective reflections, and judgements on those experiences in as much detail as needed (Smith et al., 2009). Hence, given the novelty of DMCs as a newly postulated motivational construct on the one hand, and limited empirical research investigating its various aspects on the other, IPA contributes to better understanding the phenomena, and helps explain the impacts it brings to the usual flow of life of individuals.

\section{The Participant}

The participant of this study was Ramin (pseudonym), a native speaker of Farsi, age 26. At the time of conducting this research, he was a student in civil engineering in a university in Tehran, Iran. Working a part-time job as an English language teacher in a private institute in Tehran, Ramin is a proficient speaker of English (based on his IELTS band score 7.5), and he is trying to become a capable and accomplished engineer in the future, with the hope of finding a job in a Western country. Ramin has been learning English for the past 10 years and, despite having no academic and educational background in English language teaching, he is regarded as a very successful language teacher. At the time of conducting this study, he was teaching students from different proficiency levels. The first author worked with Ramin as a colleague three years prior to June 2018, when we learned that he was going to start learning German by using the Busuu app installed on his Android smartphone. Because of our interest in researching motivational aspects of language learning beyond the classroom, we 
asked Ramin to participate in a research study investigating his language learning experience and motivation over time. The researchers adhered to ethical considerations by assuring the participant regarding the confidentiality of obtained data and informing him on the nature of study.

\section{Procedure and Interview Schedule}

In order to understand Ramin's initial motivation for learning German, the first author conducted a short semistructured interview during the first month of the study (i.e., June, 2018), and he was in prolonged contact with him through a social media network, obtaining his diary reports, and conducting interviews every two months, to track down various aspects of his language learning experience. In the last week of February 2019, after eight months of independent learning of German, Ramin reported an unusual surge in his motivation for learning German, and as some of the characteristics of DMCs were evident in his descriptions, we asked him to participate in an interview (semi-structured) that same week and encouraged him to write short daily reports about this phenomenon and the way it impacted his learning and daily life. We obtained these short descriptions via a social media network (i.e., Telegram), and used them to formulate follow-up interview questions. This enhanced motivational state lasted around five weeks and Ramin's motivation for learning German declined considerably afterward. At the end of this unusual and intense motivational period, we conducted another interview with him to gain a fuller understanding of the phenomenon and the way it influenced his language learning. The final interview lasted for two hours.

\section{Data Analysis}

Obtained data from diary reports and semi-structured interviews were analyzed using Nvivo software (version 10). In line with IPA traditions, a close reading of the transcriptions and a critical understanding based on interpretative activity (Eatough \& Smith, 2008, 2017; Smith et al., 2009) was followed by a cyclical and evolving process of coding and recoding (Saldana, 2013). In first cycle analysis, in vivo and holistic coding methods were used to divide each interview or diary section into segments related to various aspects of the learner's motivation and learning experience. In second cycle analysis, evolved codes from the first cycle were used for recoding, categorizing, or discarding by cross-referencing within and across interview transcripts and diary reports. Finally, pattern coding was used to aggregate similar codes into categories to describe the learner's experience (for example positive emotionality). Moreover, to ensure credibility in the current study, our findings and interpretations were discussed with the participant during informal meetings and two colleagues who were familiar with qualitative methods were asked to review the transcriptions, coding processes, and findings.

\section{Results}

In the following subsections, we turn to describing the participant's experience in terms of the core characteristics of DMCs (i.e., a salient facilitative structure, goal/vision orientedness, and positive emotionality).

\section{A Salient Facilitative Structure}

Before experiencing a DMC, Ramin's motivation had gone through occasional fluctuations over time but he was still able to maintain his general interest and determination in his independent learning of German as a foreign language. After six months of learning German and experiencing many motivational ups and downs, Ramin experienced a state of declined motivation that lasted for two months. During this period, he stopped completing new lessons and only used the Busuu app for vocabulary practice and sometimes for reviewing previously learned lessons. The following are some short extracts from his diaries obtained in this period:

After completing some lessons [20 out of 27] in beginner level, I can't really keep on going at this time, and [I] need to go back and maybe redo some lessons again and study grammar. (Diary entry, 11/15/2018)

I'm still looking forward with hope and always think about my goal for learning German. However, I have lost some [of] my confidence and motivation because of difficulties I face in completing new lessons. The experience of learning is not that much fun anymore, and [it] is full of frustration, anger and sometimes confusion. (Diary entry, 11/23/2018) 
Frankly speaking, I'm not that optimistic about my ability to learn German with Busuu anymore. This app is only useful in learning vocabulary. (Diary entry, 11/28/2018)

As it is evident from Ramin's diary entries, this period of declined motivation was associated with his experiencing many negative emotions such as frustration, anger, and confusion. However, he was able to continue toward his goal of learning German and, by regulating his emotions and learning goals, he was able to maintain his motivation and long-term commitment, which provided him with a context for experiencing a DMC. For the participant of this study, the triggering stimulus for launching a DMC was a German sentence, displayed on TV at the beginning of a movie.

Yesterday, I saw a German movie on TV which was dubbed in Persian, but I was able to understand some writings at the start of the film. One particular sentence which I understood was «Ein Film von» [a film by]. After seeing this sentence, I don't know what happened, but I became so excited. I realized that I have really learned German, and decided to continue my Busuu German course, and finish what I have started some months ago. (Diary entry, 2/23/2019)

When asked to elaborate on this particular incident in the first interview, Ramin recounted that experience as follows:

I don't know how to explain that, but by reading this sentence, I realized that all my hard work and persistence in learning is finally paying off and I am able to read something in German and understand it. In just a few minutes, I reached my smartphone, and decided to reset all lessons and go back to [the] first unit, and [to] finish reviewing the whole beginner level in one week or two to get my first certificate in German...I know it may sound a little weird or even stupid...but that's how it all started. (Interview data, 2/27/2019)

After the launch of the DMCs, Ramin developed some study routines associated with clearly set sub-goals in his learning of the German language. For example, he reported using every minute of his free time at work to learn German, and also talked about how he uninstalled all of the games from his smartphone to focus only on learning German.

On average, currently I am spending more than two hours every day on my learning, and I have stopped doing everything else except going to work and studying German. While I was at work today, I used every free time and moment I got to practice my German lessons. As I complete new lessons and learn more, I feel more excited about what I am doing. (Diary data)

I also uninstalled all the games and time-wasting applications from my smartphone to concentrate more on German learning with Busuu app. I remember one evening I was so busy learning German that my mom asked me several times to put it [i.e. the smartphone] aside, but I explained to her that I'm not playing games or surfing the net, but studying. I really needed to finish reviewing some lessons that day. (Interview data)

Ramin also mentioned that during this period, he had strong a commitment to achieving daily and weekly set sub-goals. In this regard, he reported changing his daily routines and actions, which was noticed by his family members.

During the past days, I did my best to use every possible chance to review and study my lessons. One day, I was unable to study as I was so busy, so I got up very early in the morning the next day to compensate for that. This was very interesting to my family especially to my mom who always complains about how I get up very late on days that I'm at home. (Interview data)

After five weeks, Ramin completed level one of the German course and took the final test. After getting his certificate, he lost a lot of his energy and enthusiasm for learning German and reverted back to old studying habits. This was clearly the end of his intense language learning activity.

After these five exciting and wonderful weeks, I don't really know how I am going to continue learning German. On the one hand, I want to go on and finish the next level in three weeks too. But I know that I can't do that anymore. I'm 
pretty sure that I'm not going to stop working on my German learning, but maybe it is going to take me some time to finish level two. (Interview data)

\section{Goal/Vision Orientedness}

During a short period of five weeks, Ramin was deeply involved with his learning of German, and by reviewing all his previously studied lessons he invested a great deal of effort to complete the beginner level German course in the Busuu app. In this regard, he initially set a deadline of two weeks for finishing the first level of the German course, however, this period was extended to five weeks. Data obtained from his short diary reports clearly pointed to the goal/vision orientedness of most of his language learning activities over the five weeks. The superordinate goal for Ramin was finishing the first level of the course in order to get the first certificate in German.

I hope to revise and re-study all 30 lessons in two weeks and get my first certificate in German. I can't wait for that.

I am extremely committed to what I have promised myself, and I want to finish reviewing all lessons in two weeks, no matter what happens.

I think I have done great during the past days, and getting my first certificate is no longer a dream. I have completed half of the course in just one week, and [I am] going to finish it soon. I can already see my name on the certificate.

This self-in-future image is the power that keeps the current level of motivation going. According to Henry et al. (2015) the power of the DMC is determined by the extent to which a visionary dimension is superimposed onto the goal. Dörnyei and Kubanyiova (2014) define a vision as a goal that is enriched by some sensory elements related to the actual experience of achieving it. In the case of Ramin, having this clear vision was expressed by seeing his name on the certificate before finishing the course. Moreover, according to Henry et al. (2015), for a language learner experiencing a DMC, the future-oriented image (or self) becomes part of his/her identity. This identity development was mentioned by Ramin as he started to express his new identity as a German language learner and user in his daily interactions.

I have also noticed that I am using every possible opportunity to tell people around me that I am learning German. It feels really great. I keep talking about how German is different from English and Persian. Sometimes I use German equivalents of some Persian and English words when talking to my friends, family and also my students. (Diary data)

I really want to learn it. I both like the idea of being able to speak German myself, and also the fact that other people consider me [as] someone who is able to speak two important languages. (Interview data)

This new identity development is also in line with the concept of 'transportable identity' proposed by Ushioda (2011) to capture the connection between language learners' target language speaking self and their personal characteristics and lived experiences.

I also installed an app on my Smartphone, German learning with Deutsche welle, but couldn't find time to use it and complete a lesson. However, when I started the app, I listened to [the] first conversation which was mainly about greetings among different people (formal and informal) and since I was able to understand most of them, I felt great and talked about this to a friend and explained how my learning of German was effective. (Interview data)

\section{Positive Emotionality}

The most important finding of the current study is related to positive emotionality associated with the experience of a DMC. As mentioned in the previous section, Ramin was learning German for eight months before being caught up in a DMC. In this regard, analyzing and comparing his accounts related to the emotional dimension of language learning before and during the experience of the DMC, shed some light on how some activities that were previously associated with negative emotions can be perceived with positive emotionality during the DMCs experience. 
Analysis of the data before the DMC and during the eight months of self-study by Ramin revealed that German grammar, spelling, and pronunciation were the three major sources for negative emotions experienced in the learning process. There were many references in the diary reports to these aspects of language learning, mostly associated with a variety of negative emotions including fear, anxiety, anger, frustration, and disappointment. More specifically, Ramin mentioned that he needed a safe place to practice German pronunciation as he was afraid of practicing German words when other people were around him. Learning German grammar on the other hand was mostly linked to anger and frustration.

I feel really bad when I can't move forward. Today, I made several mistakes again and again in completing grammar exercises. All the way home (I think it took about 20 minutes to complete the last grammar review) I felt anger and frustration and disappointment. What I'm going to do with grammar? (Diary data)

Even after practicing by myself, I thought that my pronunciation is not good at all but annoying. I think I need a safe and quiet place to practice my German pronunciation. When there are other people around me, I skip pronunciation exercises. (Diary data)

... at both situations, I enjoyed the overall experience. However, when I was wrong in spelling words, I became angry and frustrated. You start a lesson with joy, and then suddenly spelling exercises take the fun out of learning! (Diary data)

However, during the DMC, the same aspects were perceived differently and positively by Ramin. For example, in his diary reports there was plenty of evidence of a significant change of his attitude toward German pronunciation and spelling, as he reported practicing German words out loud and in front of his family members and friends.

As I go further, the things are getting harder again with grammar, but that is nothing to be afraid of. I know that I can do it and beat the grammar. Unlike before, I felt more confident today to practice some German words out loud when others were around. I think I can pronounce them correctly enough, and this feeling is great. (Diary data)

When asked to talk about these aspects during the interview session, Ramin provided further examples from how positive emotional loading changed the way he perceived learning activities.

The funny thing was that even spelling was not that annoying as it was before. While reviewing a lesson, I was more careful, and paid extra attention to spelling of difficult words and partly based on what I was able to remember, and partly with the help of Google keyboard, I did very well in answering the questions. (Interview data)

Another aspect of Ramin's experience in relation to positive emotionality was his level of engagement with the task of language learning. In this regard, he reported being occupied with, and thinking about, his German learning in this period even when he was doing other activities. He also mentioned experiencing flow-like states during the five weeks.

I remember how it was when I was deeply involved with doing German lesson with Busuu. For example, when studying at home, I remember forgetting other things that I had to do and working with the app nonstop. When you start a lesson in a quiet place, you don't really want to stop it, because it's full of joy and excitement. (Interview data)

The accounts provided by the participant clearly point to the fact that the positive emotional loading in a DMC is not a result of doing the activities related to language learning; the enjoyment stems from perusing the vision one creates for the future.

\section{Discussion}

The current study investigated a short-term intense motivational period in self-directed and mobile-assisted language learning experienced by an Iranian person learning German as a foreign language. The study used the interpretative phenomenological analysis (Aagaard, 2017; Eatough \& Smith, 2008, 2017; Smith et al., 2009) to capture the lived experience and the universal essence of being caught in a DMC. The findings in general 
provided empirical evidence supporting the potential of DMCs as a novel motivational construct to account for intense motivational behavior in the pursuit of highly valued goals and visions (Dörnyei et al., 2015; Dörnyei, Ibrahim, et al., 2014; Dörnyei, Muir, et al., 2014; Henry, 2019; Muir \& Dörnyei, 2013). In this regard, the current study provided additional support for the validity of the proposed framework for the DMCs in terms of its three core components including (1) being goal/vision-oriented, (2) having a salient facilitative structure, and (3) positive emotionality. The results are in line with previously conducted studies investigating the validity the DMC construct (García-Pinar, 2020; Ghanizadeh \& Jahedizadeh, 2017; Henry et al., 2015; Ibrahim, 2016b; Safdari \& Maftoon, 2017; Zarrinabadi et al., 2019; Zarrinabadi \& Khajeh, 2021; Zarrinabadi \& Khodarahmi, 2021; Zarrinabadi \& Tavakoli, 2017).

By using an IPA methodology, the current study also highlighted the importance of the third dimension of DMC construct, namely, positive emotional loading, in sustaining and energizing motivational effort for language learning. Given that the IPA has great potential for capturing lived experiences, the data obtained from the participant provided extensive accounts on the processes that comprised a multitude of feelings and emotions. The fact that some learning activities that were associated with negative emotions before the launch of the DMC and were then perceived with positive emotionality during this intense motivational experience deserves further attention. Based on the broaden-and-build theory of positive emotions (Fredrickson, 2013), experiences of fleeting positive emotions have long lasting consequences on individuals' growth and social connections, and these positive emotions transform peoples' lives for the better. More specifically, "positive emotions broaden an individual's momentary mindset, and by doing so help to build enduring personal resources" (Fredrickson, 2003, p. 332). Additionally, a considerable number of empirical studies support the idea that experiencing and expressing positive emotions, has a direct influence on both quality and quantity of life (Fredrickson, 2004). From this perspective, in line with the recent interest in the affective side of language learning and teaching (Agudo, 2018; Dewaele \& Li, 2018; Richards, 2020; Teimouri, 2017), the experience of DMCs can have a significant impact on the long-term motivation of language learners.

The current study also examined the start of DMCs. The findings indicated that a seemingly trivial encounter with the German language on TV was a triggering stimulus for the launch of a DMC for the participant of the study. The motivational surge was directed toward achieving a distant goal, which was earning the first certificate in German. In light of complexity theory (Larsen-Freeman \& Cameron, 2008), and the current emphasis on dynamic systems theory as the epistemological foundation for conceptualizing language learning motivation (Schumann, 2014), it could be argued that this seemingly insignificant encounter with the German language on TV resulted in a so-called butterfly effect with some unpredictable consequences for language learning outcomes (Larsen-Freeman, 2014). In this regard, the current study identified a new triggering event in addition to those mentioned by earlier studies that might have potential for launching DMCs during language study (Ibrahim, 2017; Zarrinabadi et al., 2019; Zarrinabadi \& Khodarahmi, 2021).

From a pedagogical perspective, the study demonstrated that new learning environments such as those using mobile devices and language learning applications designed for self-directed learning have great potential when learners are highly motivated. Moreover, previous studies have indicated that DMCs can have positive impacts on other learner-related factors such as willingness to communicate (WTC) and self-confidence (Zarrinabadi et al., 2019; Zarrinabadi \& Khajeh, 2021). As highlighted by Henry et al. (2015), despite the unique nature of DMCs for every individual, providing the right facilitative conditions for their emergence might result in the successful launch of intense motivational efforts that eventually contribute to developments in second language learning. In this regard, language teachers might consider using the findings from the current study and from the previous research conducted in this area to provide the facilitative conditions for DMCs to be experienced. In such undertakings, it is possible to deliberately trigger the launch of DMCs through focused interventions or group project work that provide learners with a clear vision of their desired future (Dörnyei et al., 2015; García-Pinar, 2020).

\section{Conclusion}

Directed Motivational Currents (DMCs) provided us with a new perspective for understanding highly motivated language learning experiences among learners. Given the limited empirical literature investigating different aspects of DMCs, the current IPA study investigated the intense motivational experience of an Iranian learner 
during self-directed language learning. The findings shed light on the core components of the DMC framework and the importance of the affective dimensions of DMCs. The current study had some limitations that should be acknowledged. First, given that finding individuals who are experiencing DMCs is somewhat difficult, we investigated the experience of one language learner only. Although we used various data collection methods and conducted the study longitudinally, the findings might not be generalizable to account for the experiences of other language learners. Second, studies on emotions have always been associated with methodological challenges. Despite using IPA to capture the essence of the lived experience for the participant, due to the sensitive nature of talking about emotions and feelings, this study only provides a partial picture of the emotions that might be leading to the DMCs. In this regard, further research is needed to understand the impacts of DMCs on language learning.

\section{Declaration of Competing Interest}

None declared.

\section{References}

Aagaard, J. (2017). Introducing postphenomenological research: a brief and selective sketch of phenomenological research methods. International Journal of Qualitative Studies in Education, 30(6), 519-533. https://doi.org/10. 1080/09518398.2016.1263884

Agudo, J. de D. M. (Ed.). (2018). Emotions in Second Language Teaching: Theory, research and teacher education. Springer International Publishing. https://doi.org/10.1007/978-3-319-75438-3

Arvanitis, P. (2019). Self-Paced Language Learning Using Online Platforms. In M. Dressman, \& R. W. Sadler (Eds.), The handbook of informal language learning (pp. 117-138). Wiley-Blackwell. https://doi. org/10.1002/9781119472384.ch8

Boo, Z., Dörnyei, Z., \& Ryan, S. (2015). L2 motivation research 2005-2014: Understanding a publication surge and a changing landscape. System, 55, 145-157. https://doi.org/10.1016/j.system.2015.10.006

Chik, A. (2019). Motivation and informal language learning. In M. Dressman, \& R. W. Sadler (Eds.), The handbook of informal language learning (pp. 13-26). Wiley-Blackwell. https://doi.org/10.1002/9781119472384.ch1

Cole, J., \& Vanderplank, R. (2016). Comparing autonomous and class-based learners in Brazil: Evidence for the present-day advantages of informal, out-of-class learning. System, 61, 31-42. https://doi.org/10.1016/j. system.2016.07.007

Csikszentmihalyi, M. (2014a). Applications of flow in human development and education. Springer Netherlands.

Csikszentmihalyi, M. (2014b). Flow and the foundations of positive psychology. Springer Netherlands.

Dewaele, J.-M., \& Li, C. (2018). Editorial: Special issue on emotions in second language acquisition. Studies in Second Language Learning and Teaching, 8(1), 15-19. https://doi.org/10.14746/ssllt.2018.8.1.1

Dörnyei, Z., Henry, A., \& Muir, C. (2015). Motivational currents in language learning: Frameworks for focused interventions. Routledge.

Dörnyei, Z., Ibrahim, Z., \& Muir, C. (2014). 'Directed Motivational Currents': Regulating complex dynamic systems through motivational surges. In Z. Dörnyei, P. D. MacIntyre, \& A. Henry (Eds.), Motivational dynamics in language learning (pp. 95-105). Multilingual Matters.

Dörnyei, Z., \& Kubanyiova, M. (2013). Motivating learners, motivating teachers: Building vision in the language classroom. Cambridge University Press.

Dörnyei, Z., Muir, C., \& Ibrahim, Z. (2014). Directed motivational current: Energising language learning through creating intense motivational pathways. In D. Lasagabaster, A. Doiz, \& J. M. Sierra (Eds.), Motivation and foreign language learning: From theory to practice (pp. 9-29). John Benjamins Publishing Company.

Eatough, V., \& Smith, J. A. (2008). Interpretative phenomenological analysis. In C. Willig, \& W. S. Rogers (Eds.), The SAGE handbook of qualitative research in psychology (pp. 179-194). SAGE Publications.

Eatough, V., \& Smith, J. A. (2017). Interpretative Phenomenological analysis. In C. Willig, \& W. S. Rogers (Eds.), The SAGE handbook of qualitative research in Psychology (pp. 193-209). SAGE Publications Ltd. https://doi. org/10.4135/9781526405555.n12

Fredrickson, B. L. (2003). The Value of positive emotions: The emerging science of positive psychology is coming to understand why it's good to feel good. American Scientist, 91(4), 330-335. http://www.jstor.org/ stable/27858244 
Fredrickson, B. L. (2004). Gratitude, like other positive emotions, broadens and builds. In R. A. Emmons, \& M. E. McCullough (Eds.), The Psychology of gratitude (pp. 145-166). Oxford University Press. https://doi. org/10.1093/acprof:oso/9780195150100.003.0008

Fredrickson, B. L. (2013). Chapter one - Positive emotions broaden and build. In P. Devine\& A. Plant (Eds.), Advances in Experimental Social Psychology (vol. 47, pp. 1-53). Academic Press. https://doi.org/10.1016/B9780-12-407236-7.00001-2

García-Pinar, A. (2020). Group Directed Motivational Currents: transporting undergraduates toward highly valued end goals. The Language Learning Journal, 1-13. https://doi.org/10.1080/09571736.2020.1858144

Gardner, D., \& Yung, K. W. H. (2017). Learner motivation in self-access language learning. Innovation in Language Learning and Teaching, 11(2), 159-176. https://doi.org/10.1080/17501229.2015.1088545

Ghanizadeh, A., \& Jahedizadeh, S. (2017). Directed motivational currents: The implementation of the dynamic web-based persian scale among Iranian EFL learners. Journal of Teaching Language Skills, 36(1), 27-56. https://doi.org/10.22099/jtls.2017.23952.2159

Godwin-Jones, R. (2011). Mobile apps for language learning. Language Learning \& Technology, 15(2), 2-11.

Henry, A. (2019). Directed motivational currents: Extending the theory of L2 Vision. In M. Lamb, K. Csizér, A. Henry, \& S. Ryan (Eds.), The Palgrave handbook of motivation for language learning (pp. 139-161). Palgrave Macmillan.

Henry, A., Davydenko, S., \& Dörnyei, Z. (2015). The anatomy of directed motivational currents: Exploring Intense and enduring periods of L2 motivation. The Modern Language Journal, 99(2), 329-345. https://doi. org/10.1111/modl.12214

Ibrahim, Z. (2016a). Affect in directed motivational currents: positive emotionality in long-term L2 engagement. In P. D. MacIntyre, T. Gregersen, \& S. Mercer (Eds.), Positive Psychology in SLA (pp. 258-281). Multilingual Matters. https://doi.org/10.21832/9781783095360-012

Ibrahim, Z. (2016b). Directed motivational currents: Optimal productivity and long-term sustainability in second language acquisition. University of Nottingham.

Ibrahim, Z. (2017). Parameters inducing motivational surges in second language learning. UKH Journal of Social Sciences, 1(1), 24-33. https://doi.org/10.25079/ukhjss.v1n1y2017.pp24-33

Ibrahim, Z., \& Al-Hoorie, A. H. (2019). Shared, sustained flow: Triggering motivation with collaborative projects. ELT Journal, 73(1), 51-60. https://doi.org/10.1093/elt/ccy025

Larsen-Freeman, D. (2014). Ten 'Lessons' from Complex dynamic systems theory: What is on offer. In Z. Dörnyei, P. D. MacIntyre, \& A. Henry (Eds.), Motivational dynamics in language learning (pp. 31-39). Multilingual Matters.

Larsen-Freeman, D., \& Cameron, L. (2008). Complex systems and Applied Linguistics. Oxford University Press.

Locke, E. A., \& Latham, G. P. (2013). Goal Setting Theory, 1990. In E. A. Locke, \& G. P. Latham (Eds.), New Developments in goal setting and task performance (pp. 3-15). Routledge.

Loewen, S., Isbell, D. R., \& Sporn, Z. (2020). The effectiveness of app-based language instruction for developing receptive linguistic knowledge and oral communicative ability. Foreign Language Annals, 53(2), 209-233. https://doi.org/10.1111/flan.12454

Muir, C., \& Dörnyei, Z. (2013). Directed motivational currents: Using vision to create effective motivational pathways. Studies in Second Language Learning and Teaching, 3(3), 357-375. https://doi.org/10.14746/ ssllt.2013.3.3.3

Muir, C., \& Gümüş, Ö. (2020). Directed motivational currents: An agenda for future research. Eurasian Journal of Applied Linguistics, 6(3), 501-519. https://doi.org/10.32601/ejal.834661

Pietluch, A. (2018). Extraordinary Motivation or a high sense of personal agency: the role of self-efficacy in the directed motivational currents theory. New Horizons in English Studies, 3, 45-56. https://doi.org/10.17951/ nh. 2018.45

Richards, J. C. (2015). The changing face of language learning: learning beyond the classroom. RELC Journal, 46(1), 5-22. https://doi.org/10.1177/0033688214561621

Richards, J. C. (2020). Exploring Emotions in language teaching. RELC Journal. https://doi. org/10.1177/0033688220927531

Rosell-Aguilar, F. (2018). Autonomous language learning through a mobile application: A user evaluation of the busuu app. Computer Assisted Language Learning, 31(8), 854-881. https://doi.org/10.1080/09588221.2018.1 456465

Safdari, S., \& Maftoon, P. (2017). The Rise and fall of directed motivational currents: A case study. The Journal of Language Learning and Teaching, 7(1), 43-54.

Saldana, J. (2013). The coding manual for qualitative researchers. SAGE Publications Ltd. 
Schumann, J. H. (2014). Foreword. In Z. Dörnyei, P. D. MacIntyre, \& A. Henry (Eds.), Motivational dynamics in language learning (pp. xv-xix). Multilingual Matters.

Smith, J. A., Flowers, P., \& Larkin, M. (2009). Interpretative phenomenological analysis: Theory, method and research. SAGE Publications Ltd.

Teimouri, Y. (2017). L2 Selves, emotions, and motivated behaviors. Studies in Second Language Acquisition, 39(4), 681-709. https://doi.org/10.1017/S0272263116000243

Ushioda, E., \& Dörnyei, Z. (2012). Motivation. In S. M. Gass, \& A. Mackey (Eds.), The Routledge handbook of second language acquisition (pp. 396-409). Routledge.

Xodabande, I. (2018). Iranian EFL Learners' preferences of different digital technologies for language learning beyond the classroom. International Journal of Education and Literacy Studies, 6(3), 20-31. https://doi. org/10.7575/aiac.ijels.v.6n.3p.20

Xodabande, I., \& Atai, M. R. (2020). Using mobile applications for self-directed learning of academic vocabulary among university students. Open Learning: The Journal of Open, Distance and e-Learning, 1-18. https://doi.or $\mathrm{g} / 10.1080 / 02680513.2020 .1847061$

Zarrinabadi, N., Ketabi, S., \& Tavakoli, M. (2019). Directed motivational currents in L2: Exploring the Effects on self and communication. Springer International Publishing.

Zarrinabadi, N., \& Khajeh, F. (2021). Describing characteristics of group-level directed motivational currents in EFL contexts. Current Psychology. https://doi.org/10.1007/s12144-021-01518-9

Zarrinabadi, N., \& Khodarahmi, E. (2021). Some antecedents of directed motivational currents in a foreign language. Journal of Multilingual and Multicultural Development, 1-14. https://doi.org/10.1080/01434632.20 21.1931250

Zarrinabadi, N., \& Tavakoli, M. (2017). Exploring Motivational surges among Iranian EFL teacher trainees: Directed motivational currents in focus. TESOL Quarterly, 51(1), 155-166. https://doi.org/10.1002/tesq.332 